\title{
Aplikasi Model Generalized Space Time Autoregressive (GSTAR) pada Data Jumlah TKI Jawa Barat dengan Pemilihan Lokasi Berdasarkan Klaster DBSCAN
}

\author{
Herlin Dewi Karlina, Rini Cahyandari, Asep Solih Awalluddin \\ Jurusan Matematika, Fakultas Sains \& Teknologi, UIN SGD Bandung \\ Jl. A. H. Nasution No. 105 Cibiru-Bandung 40614 \\ herlin.math09@gmail.com, rcahyandari@yahoo.com, aasolih@gmail.com
}

\begin{abstract}
ABSTRAK
Menurut data BNP2TKI Indonesia, Jawa Barat tercatat sebagai provinsi yang paling banyak menempatkan warganya bekerja ke luar negeri dengan fungsi pekerjaan didominasi sebagai sektor pekerja rumah tangga. Karena itu, pemodelan jumlah TKI tiap kota/kabupaten wilayah Jawa Barat perlu dibuat sebagai pertimbangan untuk mengatasi permasalahan TKI dalam perencanaan penciptaan lapangan kerja bagi masyarakat. Model statistika yang digunakan adalah Generalized Space Time Autoregressive (GSTAR) yang merupakan perluasan model STAR yang mampu mempertimbangkan faktor lokasi dan waktu secara simultan, sehingga model yang dihasilkan akan meningkatkan tingkat akurasi dalam meramalkan jumlah TKI Jawa Barat pada masa mendatang. Pemilihan lokasi kabupaten wilayah Jawa Barat berdasarkan analisis klaster Density Based on Spatial Clustering with Noise (DBSCAN), yaitu pembentukan klaster berdasarkan pada koneksi dan fungsi densitas. Pada penelitian ini diperoleh 3 klaster wilayah, yaitu: klaster 1 sebanyak 13 lokasi, klaster 2 sebanyak 3 lokasi, dan klaster 3 ada 1 lokasi. Matriks bobot lokasi yang digunakan adalah matriks dengan bobot biner, bobot seragam, dan bobot korelasi silang. Identifikasi model menggunakan STACF dan STPACF menunjukkan model yang sesuai dengan data adalah model GSTAR(10) dan GSTAR $\left(1_{1}\right)$ dengan matriks bobot biner dan korelasi silang. Estimasi parameter menggunakan metode Odinary Least Square (OLS) memberikan model terbaik adalah model GSTAR(10) yang memiliki nilai Root Mean Squared Error (RMSE) terkecil dengan nilai RMSE sebesar 21,4651.
\end{abstract}

Kata kunci: DBSCAN, GSTAR, STACF, STPACF, OLS, RMSE.

\section{ABSTRACT}

According to data from Indonesia BNP2TKI. West Java province was recorded as the most put citizens to work abroad with job functions predominantly as a domestic worker sector. Therefore, modeling the number of migrants each city/county region of West Java consideration needs to be made as to overcome the problems of migrant workers in the planning of job creation for the people. Statistical model used is the Generalized Space Time Autoregressive (GSTAR) which is an extension of the STAR models capable of taking into account the location and time simultaneously, so that the resulting model will increase the level of accuracy in predicting the number of migrant workers in West Java in the future. Site selection in West Java location based on cluster analysis Density Based Spatial Clustering with Noise (DBSCAN), namely the formation of clusters based on the density of connections and functions. In this study obtained 3 cluster region, namely: Cluster 1 as many as 13 locations, 3 locations as cluster 2, and cluster 3 there is 1 location. location weights used is a binary matrix with weights, weights uniform, and the weight of the cross-correlation. Identification model using STACF and STPACF shows that the model fits the data is GSTAR (10) and GSTAR (1 $\left.1_{1}\right)$ with binary weights matrix and cross-correlation. Estimation parameter using Odinary Least Square method (OLS) gives the best model is the GSTAR (10) which has a value of Root Mean Squared Error (RMSE) with the smallest RMSE value of 21.4651.

Keywords: DBSCAN, GSTAR, STACF, STPACF, OLS, RMSE.

\section{Pendahuluan}

Tenaga Kerja Indonesia adalah sebutan bagi warga negara Indonesia yang bekerja di luar negeri dalam hubungan kerja untuk jangka waktu tertentu dengan menerima upah. Alasan terbesar menjadi TKI adalah faktor ekonomi dan tidak adanya lapangan kerja di Indonesia. TKI sering disebut sebagai pahlawan devisa Negara, karena devisa yang dihasilkan TKI per tahun merupakan penyumbang terbesar kedua setelah sektor minyak dan gas bumi. TKI perempuan seringkali disebut Tenaga Kerja Wanita (TKW), bahkan Tenaga Kerja Indonesia didominasi oleh perempuan. 
Oleh karena itu, perlu dibuat pola data jumlah TKI di Jawa Barat, sehingga dapat menggunakannya untuk peramalan jumlah TKI Jawa Barat di masa mendatang dengan harapan dapat menjadi pertimbangan dalam pengambilan keputusan oleh Pemerintah Provinsi maupun pemerintah daerah dalam menangani permasalahan TKI. Data jumlah TKI di Jawa Barat diperkirakan memiliki keterkaitan faktor waktu dan lokasi sehingga dapat diselesaikan dengan model space time. Namun, jumlah TKI tiap daerah memiliki keheterogenan, diantaranya disebabkan tingkat kemiskinan/ekonomi tiap daerah berbeda, sehingga mengakibatkan jumlah TKI tiap kota/kabupaten yang ada di Jawa Barat berbeda-beda. Model yang sesuai untuk menyelesaikan kasus ini adalah model Generalized Space Time Autoregressive (GSTAR). Jawa Barat memiliki 21 kota/kabupaten, sehingga diperlukan pemilihan lokasi. Pada penelitian ini, pemilihan lokasi berdasarkan pengelompokan data menggunakan metode klaster Density Based on Spatial Clustering with Noise (DBSCAN), yaitu pembentukan klaster berdasarkan pada koneksi dan fungsi densitas.

Model GSTAR yang digunakan yaitu GSTAR (1 $\left.1_{1}\right)$ dengan lag time $t=1$ dan lag spasial $l=1$. Model space time memerlukan matriks bobot lokasi untuk merepresentasikan faktor lokasi, sehingga matriks bobot lokasi yang digunakan pada penelitian ini adalah bobot lokasi biner, seragam, dan korelasi silang. Metode estimasi menggunakan metode kuadrat terkecil. Model terbaik akan dipilih dengan berdasarkan nilai RMSE terkecil.

\subsection{Model Generalized Space Time Autoregressive (GSTAR)}

Model GSTAR merupakan perluasan model STAR, sehingga model umum GSTAR sama dengan model umum STAR. Parameter-parameter model GSTAR bersifat heterogen baik faktor waktu maupun lokasi. Model GSTAR diperkenalkan (Ruchjana (2002) [4] sebagai perluasan dari model STAR (Pfeifer-Deutsch 1980). Misal $z(t)=\left(z_{i}(t), \ldots, z_{N}(t)\right)^{t}$ adalah proses vektor dimensi- $N$ dengan mean nol dan $N$ adalah bilangan bulat positif. Model $\operatorname{GSTAR}\left(p ; \lambda_{1}, \lambda_{2}, \ldots, \lambda_{p}\right)$ adalah model space time $z(t)$ yang memenuhi [4]:

dengan:

$$
z(t)=\sum_{k=1}^{p} \sum_{l=0}^{\lambda_{k}} \phi_{k l} W^{(l)} Z(t-k)+e(t)
$$

$p$ : orde waktu autoregressive,

$\lambda_{k}$ : orde spasial dari autoregressive term ke- $k$,

$\phi_{k l}$ : parameter autoregressive pada lag waktu $k$ dan lag spasial $l$, dengan elemen diagonal $\left(\Phi_{k l}^{1}, \ldots, \Phi_{k l}^{N}\right)$,

$W^{(l)}$ : $\quad$ matriks bobot ukuran $N x N$ untuk order spasial $l$ (dimana $l=0,1, \ldots, \mathrm{N}$ ) dengan $W^{(0)}$ adalah matriks identitas $\boldsymbol{I}$ dengan ukuran $N x N$,

$z(t)$ : $\quad$ vektor acak ukuran $N x 1$ pada waktu $t$

$e(t)$ : $\quad$ vektor eror pada waktu $t$ ukuran $N x 1$ diasumsikan berdistribusi normal dengan rata-rata nol dan variansi konstan.

Model GSTAR $\left(p_{1}\right)$ didefinisikan sebagai:

dengan:

$$
Z(t)=\left[\Phi_{k 0}+\Phi_{k 1} W\right] Z(t-k)+e(t)
$$

$\Phi_{k 0}=\operatorname{diag}\left(\Phi_{k 0}^{1}, \ldots, \Phi_{k 0}^{\mathrm{N}}\right), \Phi_{k 1}=\operatorname{diag}\left(\Phi_{k 1}^{1}, \ldots, \Phi_{k 1}^{N}\right) \operatorname{dan} w_{i i}=0$ dan $\sum_{i \neq j} w_{i j}=1$.

Berikut Model GSTAR(1 1 ) untuk setiap lokasi $i=1,2, \ldots, N$ dan waktu $t$ dinyatakan oleh [2]:

$$
z_{i}(t)=\phi_{10}^{(i)} z_{i}(t-1)+\phi_{11}^{(i)} \sum_{j=1}^{N} w_{i j} z_{j}(t-1)+e_{i}(t)
$$

Dalam notasi matriks, model di atas dapat dinyatakan sebagai:

dengan:

$$
Z(t)=\left[\Phi_{10}+\Phi_{11} W^{(1)}\right] Z(t-1)+e(t)
$$

$$
Z(t)=\left(\begin{array}{c}
z_{1}(t) \\
z_{2}(t) \\
\vdots \\
z_{N}(t)
\end{array}\right), \Phi_{10}=\left(\begin{array}{cccc}
\phi_{10}^{(1)} & 0 & \cdots & 0 \\
0 & \phi_{10}^{(2)} & \cdots & 0 \\
\cdots & \cdots & \ddots & \vdots \\
0 & 0 & \cdots & \phi_{10}^{(N)}
\end{array}\right), \Phi_{11}=\left(\begin{array}{cccc}
\phi_{11}^{(1)} & 0 & \cdots & 0 \\
0 & \phi_{11}^{(2)} & \cdots & 0 \\
\cdots & \cdots & \ddots & \vdots \\
0 & 0 & \cdots & \phi_{11}^{(N)}
\end{array}\right)
$$




\subsection{Tahap-tahap Pembentukan Model GSTAR}

Membangun model GSTAR mengikuti prosedur Box-Jenkins dalam pembentukan model time series yaitu identifikasi model, estimasi parameter, dan pemilihan model terbaik.

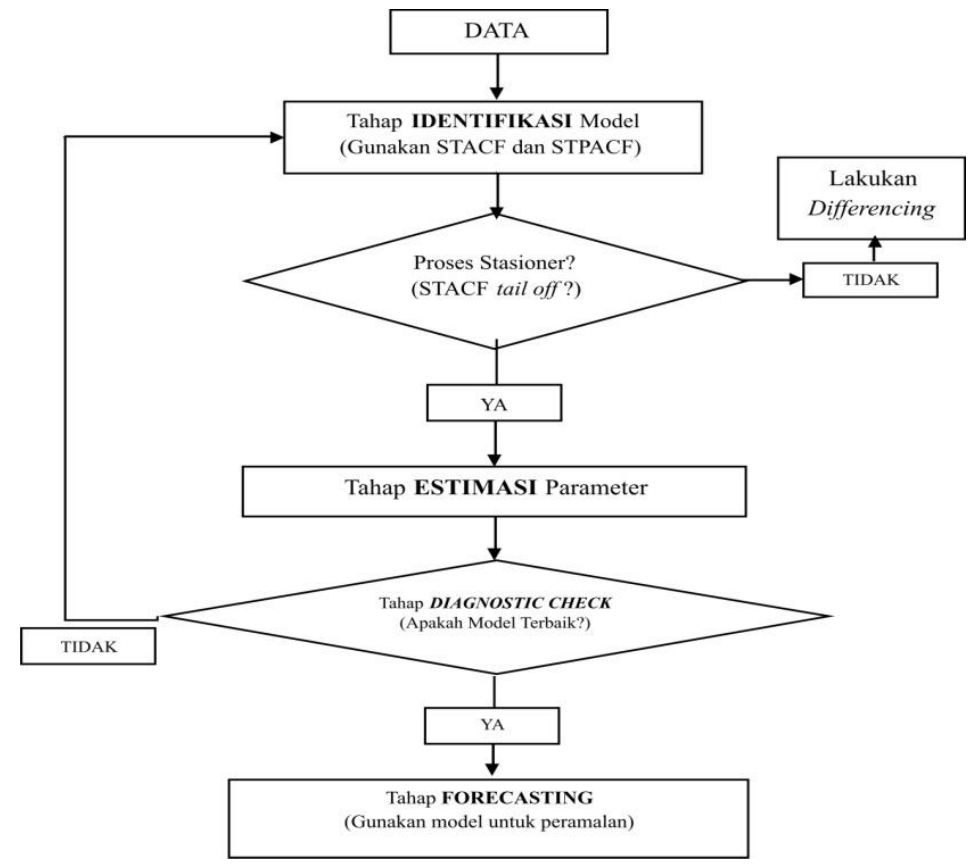

Gambar 1. Skema pembentukan Model GSTAR

\section{Identifikasi Model}

Komponen utama dalam identifikasi model space time sebagai berikut:

1. Space Time Autocorrelation Function (STACF)

Karakteristik STACF GSTAR yaitu menurun secara signifikan (tail off) yang menunjukkan data stasioner. Menghitung nilai STACF menggunakan sample space time autocorrelation function (STACF) dengan spasial lag $l=0,1, \ldots, \lambda, k=0$, dan time lag $s=1,2, \ldots, S$ didefinisikan sebagai [3]:

$$
\hat{\rho}_{l 0}(s)=\frac{\sum_{i=1}^{N} \Sigma_{t=1}^{T-S} L^{(l)} z_{i}(t) L^{(0)} z_{i}(t+s)}{\left[\sum_{i=1}^{N} \Sigma_{i=1}^{T}\left(L^{(l)} z_{i}(t)\right)^{2} \Sigma_{i=1}^{N} \Sigma_{i=1}^{T}\left(L^{(0)} z_{i}(t)\right)^{2}\right]^{\frac{1}{2}}}
$$

2. Space Time Partial Autocorrelation Function (STPACF)

Digunakan untuk melihat orde ke berapa model dari GSTAR yang paling cocok. Karakteristik STPACF model GSTAR(1 1 ) terputus (cut off) pada selang waktu $s=1$ dan spasial lag $l=1$. Menghitung nilai STPACF menggunakan persamaan [3]:

$$
\hat{\gamma}_{h 0}(s)=\sum_{j=1}^{k} \sum_{l=0}^{\lambda} \hat{\phi}_{j l} \hat{\gamma}_{h l}(s-j)
$$

dengan $s=1,2, \ldots, k$ dan $h=0,1, \ldots, \lambda$.

Spasial lag $l=0$

Spasial lag $l=1$

$$
\hat{\phi}_{s 0}=\left\{\begin{array}{c}
\frac{\hat{\gamma}_{00}(1)}{\hat{\gamma}_{00}(0)}, s=1 \\
\frac{\hat{\gamma}_{00}(s)-\sum_{i=1}^{s-1} \widehat{\phi}_{00} \widehat{\gamma}_{00}(s-i)}{\widehat{\gamma}_{00}(0)}, s=2,3,4, \ldots, k
\end{array}\right.
$$


Spasial lag $l=2$

$$
\hat{\phi}_{s 1}=\left\{\begin{array}{c}
\frac{\widehat{\gamma}_{10}(1)-\widehat{\phi}_{10} \widehat{\gamma}_{00}(0)}{\widehat{\gamma}_{11}(0)}, s=1 \\
\frac{\widehat{\gamma}_{10}(s)-\sum_{i=1}^{S-1} \sum_{j=0}^{1} \widehat{\phi}_{i j} \widehat{\gamma}_{1 j}(s-i)-\widehat{\phi}_{s 0} \widehat{\gamma}_{10}(0)}{\widehat{\gamma}_{11}(0)}, s=2,3,4, \ldots, k
\end{array}\right.
$$

Spasial lag $l=3$

$$
\hat{\phi}_{s 2}=\left\{\begin{array}{c}
\frac{\widehat{\gamma}_{20}(1)-\widehat{\phi}_{10} \widehat{\gamma}_{20}(0)-\widehat{\phi}_{11} \widehat{\gamma}_{21}(0)}{\widehat{\gamma}_{22}(0)}, s=1 \\
\frac{\widehat{\gamma}_{20}(s)-\sum_{i=1}^{S-1} \sum_{j=0}^{2} \widehat{\phi}_{i j} \widehat{\gamma}_{2 j}(s-i)-\sum_{j=0}^{1} \widehat{\phi}_{s j} \widehat{\gamma}_{2 j}(0)}{\widehat{\gamma}_{22}(0)}, s=2,3,4, \ldots, k
\end{array}\right.
$$

$$
\widehat{\phi}_{s 3}=\left\{\begin{array}{c}
\frac{\widehat{\gamma}_{30}(1)-\widehat{\phi}_{10} \widehat{\gamma}_{30}(0)-\widehat{\phi}_{11} \widehat{\gamma}_{31}(0)-\widehat{\phi}_{12} \widehat{\gamma}_{32}(0)}{\widehat{\gamma}_{33}(0)}, s=1 \\
\frac{\widehat{\gamma}_{30}(s)-\sum_{i=1}^{s-1} \sum_{j=0}^{3} \widehat{\phi}_{i j} \widehat{\gamma}_{3 j}(s-i)-\sum_{j=0}^{2} \widehat{\phi}_{s j} \widehat{\gamma}_{3 j}(0)}{\widehat{\gamma}_{33}(0)}, s=2,3,4, \ldots, k
\end{array}\right.
$$

\section{Estimasi Parameter}

Salah satu estimasi terbaik dengan menggunakan metode Ordinary least square (OLS) yaitu meminimumkan jumlah kuadrat galat didasarkan pada teori regresi linier standar $\mathrm{Y}=\mathrm{XB}+e$.

Persamaan model GSTAR

$$
z_{i}(t)=\phi_{10}^{(i)} z_{i}(t-1)+\phi_{11}^{(i)} \sum_{j=1}^{N} w_{i j} z_{j}(t-1)+e(t)
$$

Untuk $t=1,2, \ldots, T$ memberikan model linier lokasi $\mathrm{i}=1,2, \ldots, \mathrm{N}$ sebagai [5] (Ruchjana):

$$
Y_{i}=X_{i} \beta_{\mathrm{i}}+e_{i}
$$

dengan $V_{i}(t)=\sum_{j=1}^{N} w_{i j} z_{j}$.

$$
\left(\begin{array}{c}
z_{1}(1) \\
z_{1}(2) \\
\vdots \\
z_{1}(T) \\
\vdots \\
z_{N}(1) \\
z_{N}(2) \\
\vdots \\
z_{N}(T)
\end{array}\right)=\left(\begin{array}{ccccc}
z_{1}(0) & V_{1}(0) & \cdots & 0 & 0 \\
z_{1}(1) & V_{1}(1) & \cdots & 0 & 0 \\
\vdots & \vdots & \vdots & \vdots & \vdots \\
z_{1}(T-1) & V_{1}(T-1) & \cdots & 0 & 0 \\
\vdots & \vdots & \ddots & \vdots & \vdots \\
0 & 0 & \cdots & z_{N}(0) & z_{N}(0) \\
0 & 0 & \cdots & z_{N}(1) & z_{N}(1) \\
\vdots & \vdots & \vdots & \vdots & \vdots \\
0 & 0 & \cdots & z_{N}(T-1) \\
z_{N}(T-1)
\end{array}\right)\left(\begin{array}{c}
\phi_{10}^{(1)} \\
\phi_{11}^{(1)} \\
\phi_{10}^{(2)} \\
\phi_{11}^{(2)} \\
\vdots \\
\phi_{10}^{(N)} \\
\phi_{11}^{(N)}
\end{array}\right)+\left(\begin{array}{c}
e_{1}(1) \\
e_{1}(2) \\
\vdots \\
e_{1}(T) \\
\vdots \\
e_{N}(1) \\
e_{N}(2) \\
\vdots \\
e_{N}(T)
\end{array}\right)
$$

Penaksir $\beta$ yaitu $\hat{\beta}=\left(\hat{\phi}_{10}^{(1)}, \hat{\phi}_{11}^{(1)}, \ldots, \hat{\phi}_{10}^{(N)}, \hat{\phi}_{11}^{(N)}\right)^{t}$. Kuadrat terkecil parameter $\hat{\beta}$ adalah

Akibatnya,

$$
X^{t} X \hat{\beta}=X^{t} Y
$$

dimana, $X^{t} X$ harus non singular.

$$
\hat{\beta}=\left(X^{t} X\right)^{-1} X^{t} Y
$$

\section{Pemilihan Model Terbaik}

Root Mean Squared Error (RMSE) adalah ukuran perbedaan antara nilai prediksi dari model atau penaksir dengan nilai sebenarnya dari observasi.. Semakin kecil nilai RMSE, maka semakin baik model yang dipilih. Berikut rumus untuk mengetahui besarnya nilai RMSE [1]:

$$
R M S E=\sqrt{M S E}=\sqrt{\frac{1}{M} \sum_{t=1}^{M}\left(Z_{t}-\hat{Z}_{t}\right)^{2}}
$$

dengan $\mathrm{M}$ adalah banyaknya data ramalan yang digunakan.

\section{Density Based on Spatial Clustering with Noise (DBSCAN)}

DBSCAN merupakan salah satu kategori clustering density-based algorithms yaitu pembentukan klaster berdasarkan pada koneksi dan fungsi densitas membentuk area-area dengan 
kepadatan yang cukup tinggi ke dalam klaster-klaster dan menemukan klaster-klaster dalam bentuk yang sembarang dalam suatu database spasial yang memuat noise.

DBSCAN mendefinisikan klaster sebagai himpunan maksimum dari titik-titik kepadatan yang terkoneksi (density-connected). Semua objek yang tidak masuk ke dalam klaster manapun dianggap sebagai noise. Clustering berbasis densitas menempatkan daerah kepadatan tinggi yang dipisahkan dari satu sama lain oleh wilayah kepadatan rendah. Secara umum, kepadatan (density) adalah jumlah titik dalam radius tertentu $(\varepsilon)$. Salah satu software pengolahan data menjadi clustering adalah Rapid Miner.

\section{Indeks Gini}

Metode indeks Gini merupakan rasio analisis yang sangat merepresentatif data dalam masyarakat yang heterogen. Metode indeks Gini biasanya digunakan untuk mengetahui tingkat pemerataan pendapatan masyarakat dengan melihat nilai indeks Gini yang dibagi menjadi beberapa kriteria diantaranya $G n=0$ artinya pemerataan sempurna dan $G n=1$ artinya pemerataan tidak sempurna. Berikut statistik uji yang digunakan:

Dengan:

$$
G=1+\frac{1}{n}-\frac{2}{\left(n^{2} \bar{y}_{i}\right)} x \sum_{i}^{N} y_{i}
$$

$y=$ nilai variabel yang diamati

$\bar{y}=$ rata-rata nilai variabel yang diamati

$n=$ ukuran sampel

$N=$ banyak variabel yang diamati

$i=$ indeks sampel

\section{Metode Penelitian}

Data yang digunakan dalam penelitian ini adalah data sekunder yang diperoleh dari Badan Nasional Penempatan dan Perlindungan Tenaga Kerja Indonesia (BNP2TKI) Provinsi Jawa Barat. Variabel yang digunakan adalah data jumlah Tenaga Kerja Indonesia (TKI) bulanan di 21 kota/kabupaten Jawa Barat selama 29 bulan (2011-2013).

Data jumlah TKI didapatkan dari jumlah pembuat Kartu Tenaga Kerja Luar Negeri (KTKLN ) yang diproses di BNP2TKI provinsi Jawa Barat. Pemilihan lokasi berdasarkan deskriptif data dengan melihat mean, variansi, dan grafik data tiap lokasi yang hampir sama.

Tahapan analisis data yang digunakan dalam penelitian ini secara rinci sebagai berikut:

1. Pemilihan lokasi berdasarkan metode klaster DBSCAN menggunakan Rapid Miner.

2. Menghitung korelasi antar lokasi yang sudah dipilih untuk mengetahui besarnya pengaruh atau hubungan keterkaitan antara satu lokasi terhadap lokasi yang lain.

3. Menghitung nilai indeks Gini masing-masing lokasi untuk melihat keheterogenan data tiap lokasi.

4. Menentukan matriks bobot lokasi biner dan seragam.

5. Menghitung nilai bobot korelasi silang menggunakan Microsoft Excel 2007.

6. Menghitung nilai Space Time Autocorrelation Function (STACF) dan Space Time Partial Autocorrelation Function (STPACF) menggunakan Microsoft Excel 2007.

7. Mengestimasi parameter dengan Ordinary Least Square.

8. Pemilihan model terbaik dengan menghitung Root Mean Squared Error (RMSE).

\section{Hasil dan Pembahasan}

Analisis yang dilakukan meliputi pemilihan lokasi berdasarkan klaster DBSCAN dan pembentukan model GSTAR

\subsection{Pemilihan lokasi}

Pemilihan lokasi data TKI di wilayah Jawa Barat dengan cara memilih lokasi dengan klaster DBSCAN yaitu pengelompokan berdasarkan kepadatan data. Tabel 1 menyajikan statistika deskriptif data. 
Berdasarkan pengelompokkan di atas dapat dilihat bahwa kota/kabupaten yang memiliki kepadatan data paling besar terdapat pada klaster 1, kepadatan data rendah terdapat pada klaster 2, dan data outlier ada di klaster 3 yaitu kabupaten Banjar. Pembentukan model dalam penelitian ini memprioritaskan kota/kabupaten dengan kepadatan data paling tinggi di wilayah Jawa Barat. Oleh karena itu, kelompok data yang akan diolah lebih lanjut adalah kota/kabupaten yang terdapat pada klaster 1.

Tabel 1. Hasil Pengelompokan Data Menggunakan Metode DBSCAN

\begin{tabular}{|c|l|}
\hline Kelompok & \multicolumn{1}{|c|}{ Kota/Kabupaten } \\
\hline Klaster 1 & $\begin{array}{l}\text { Kuningan, Cirebon, Majalengka, Indramayu, Sumedang, Subang, } \\
\text { Purwakarta, Karawang, Sukabumi, Cianjur, Bandung Barat, Cimahi, } \\
\text { Bandung, Garut, Tasikmalaya, dan Ciamis }\end{array}$ \\
\hline Klaster 2 & Bekasi, Depok, Garut \\
\hline Klaster 3 & Banjar \\
\hline
\end{tabular}

Kota/kabupaten yang sudah dipilih harus memiliki hubungan atau keterkaitan untuk meenuhi asumsi korelasi spasial. Nilai korelasi antar kota/kabupaten dapat digunakan untuk mengetahui besarnya pengaruh atau hubungan keterkaitan antara satu kota/kabupaten terhadap kota/kabupaten yang lain. Kota/kabupaten yang akan dibuat model GSTAR adalah yang memiliki nilai korelasi antar kota/kabupaten $\geq 0,6$ yaitu menginterpretasi tingkat hubungan yang kuat.

Tabel 2. Matriks Korelasi Antar Kota/Kabupaten

\begin{tabular}{|c|c|c|c|c|c|c|c|c|c|c|c|c|c|c|c|c|}
\hline Kota & KNG & CRB & MJL & IND & SMD & SBG & PWK & KRW & SKBM & CJR & $\begin{array}{l}\text { BDG } \\
\text { BRT }\end{array}$ & $\mathrm{CM}$ & BDG & GRT & TSK & CMS \\
\hline KNG & 1 & .709 & .708 & .611 & .643 & .549 & .678 & .659 & .706 & .702 & .616 & .178 & .584 & .682 & .581 & .615 \\
\hline CRB & .709 & 1 & .953 & .912 & .882 & .894 & .856 & .818 & .893 & .917 & .629 & .495 & .848 & .896 & .832 & .889 \\
\hline MJL & .708 & .953 & 1 & .938 & .858 & .920 & .889 & .862 & .931 & .947 & .601 & .437 & .858 & .937 & .827 & .934 \\
\hline IND & .611 & .912 & .938 & 1 & .881 & .928 & .824 & .876 & .887 & .915 & .522 & .380 & .795 & .863 & .836 & .931 \\
\hline SMD & .643 & .882 & .858 & .881 & $\mathrm{I}$ & .810 & .743 & .755 & .803 & .825 & .751 & .514 & .829 & .807 & .788 & .807 \\
\hline SBG & .549 & .894 & .920 & .928 & .810 & 1 & .828 & .907 & .900 & .910 & .546 & .397 & .787 & .831 & .771 & .918 \\
\hline PWK & .678 & .856 & .889 & .824 & .743 & .828 & 1 & .850 & .910 & .933 & .605 & .328 & .780 & .876 & .729 & .837 \\
\hline KRW & .659 & .818 & .862 & .876 & .755 & .907 & .850 & $\mathrm{~T}$ & $.940^{\circ}$ & .938 & .560 & .122 & .634 & .754 & .764 & .828 \\
\hline SKBM & .706 & .893 & .931 & .887 & .803 & .900 & .910 & .940 & 1 & .959 & .658 & .318 & .791 & .876 & .833 & .876 \\
\hline CJR & .702 & .917 & .947 & .915 & .825 & .910 & .933 & .938 & .959 & 1 & .623 & .336 & .767 & .894 & .823 & .899 \\
\hline $\begin{array}{l}\text { BDG } \\
\text { BRT }\end{array}$ & .616 & .629 & .601 & .522 & .751 & .546 & .605 & .560 & .658 & .623 & 1 & .485 & .686 & .628 & .484 & .574 \\
\hline $\mathrm{CMIH}$ & .178 & .495 & .437 & .380 & .514 & .397 & .328 & .122 & .318 & .336 & .485 & 1 & .711 & .568 & .425 & .414 \\
\hline BDG & .584 & .848 & .858 & .795 & .829 & .787 & .780 & .634 & .791 & .767 & .686 & .711 & 1 & .913 & .759 & .811 \\
\hline GRT & .682 & .896 & .937 & .863 & .807 & .831 & .876 & .754 & .876 & .894 & .628 & .568 & .913 & 1 & .785 & .890 \\
\hline TSK & .581 & .832 & .827 & .836 & .788 & .771 & .729 & .764 & .833 & .823 & .484 & .425 & .759 & .785 & 1 & .746 \\
\hline CMS & .615 & .889 & .934 & .931 & .807 & .918 & .837 & .828 & .876 & .899 & .574 & .414 & .811 & .890 & .746 & 7 \\
\hline
\end{tabular}

Berdasarkan matriks korelasi pada Tabel 2 terdapat nilai korelasi antar kota/kabupaten $\leq 0,6$ yaitu Kabupaten Kuningan, Cimahi, dan Bandung Barat. Oleh karena itu, ketiga Kabupaten ini tidak masuk dalam daftar kota/kabupaten yang akan dibuat model GSTAR. Untuk selanjutnya jumlah TKI di masing-masing kota/kabupaten disebut variabel. Cirebon ( $\left.\mathrm{Z}_{1}\right)$, Indramayu ( $\left.\mathrm{Z}_{2}\right)$, Majalengka (Z $\left.\mathrm{Z}_{3}\right)$, dan Sumedang $\left(\mathrm{Z}_{4}\right)$, Subang $\left(\mathrm{Z}_{5}\right)$, Purwakarta $\left(\mathrm{Z}_{6}\right)$, Karawang $\left(\mathrm{Z}_{7}\right)$, Sukabumi $\left(\mathrm{Z}_{8}\right)$, Cianjur (Z9), Bandung $\left(\mathrm{Z}_{10}\right)$, Garut $\left(\mathrm{Z}_{11}\right)$, Tasikmalaya $\left(\mathrm{Z}_{12}\right)$, Ciamis $\left(\mathrm{Z}_{13}\right)$.

\section{Uji keherogenan:}

a. Perumusan Hipotesis

$H_{0}$ : Lokasi Homogen (kemerataan sempurna)

$H_{1}$ : Lokasi Heterogen (kemerataan tidak sempurna)

b. Besaran yang digunakan

$$
\begin{aligned}
& n=13 \times 29=377 \\
& n^{2}=142129 \\
& \bar{y}_{Z_{1}}=49,4828 \\
& \bar{y}_{Z_{2}}=46,3448
\end{aligned}
$$

$$
\begin{aligned}
& \bar{y}_{Z_{6}}=15,3793 \\
& \bar{y}_{Z_{7}}=13,7931
\end{aligned}
$$$$
\bar{y}_{Z_{11}}=26,3448
$$$$
\bar{y}_{Z_{12}}=19,6897
$$ 


$$
\begin{array}{ll} 
& \bar{y}_{Z_{3}}=38,3448 \\
& \bar{y}_{Z_{4}}=10,6207 \\
& \bar{y}_{Z_{5}}=30,7582 \\
\text { c. Statistik uji }
\end{array}
$$

$$
\begin{aligned}
G_{Z_{1}} & =1,00224444 \\
G_{Z_{2}} & =1,00224444 \\
G_{Z_{3}} & =1,00224444 \\
G_{Z_{4}} & =1,00224444 \\
G_{Z_{5}} & =1,00224444
\end{aligned}
$$

$$
\begin{array}{ll}
\bar{y}_{Z_{8}}=37,8966 & \bar{y}_{Z_{13}}=19,1379 \\
\bar{y}_{Z_{9}}=66,3793 & \\
\bar{y}_{Z_{10}}=94,6207 &
\end{array}
$$

$$
G=1+\frac{1}{n}-\frac{2}{\left(n^{2} \bar{y}_{i}\right)} x \sum_{i}^{N} y_{i}
$$

\begin{tabular}{|c|c|c|c|}
\hline Orde & 1 & 2 & 3 \\
\hline Variabel $-\mathrm{Z}_{1}$ & $\mathrm{Z}_{2}, \mathrm{Z}_{3}$ & $\mathrm{Z}_{4}, \mathrm{Z}_{13}$ & $\mathrm{Z}_{5}$ \\
\hline $\mathrm{Z}_{2}$ & $\mathrm{Z}_{1}, \mathrm{Z}_{3}, \mathrm{Z}_{4}, \mathrm{Z}_{5}$ & $\mathrm{Z}_{13}$ & $\mathrm{Z}_{10}$ \\
\hline $\mathrm{Z}_{3}$ & $\mathrm{Z}_{1}, \mathrm{Z}_{2}, \mathrm{Z}_{4}, \mathrm{Z}_{13}$ & $\mathrm{Z}_{11}, \mathrm{Z}_{12}$ & $\mathrm{Z}_{5}, \mathrm{Z}_{10}$ \\
\hline $\mathrm{Z}_{4}$ & $\mathrm{Z}_{2}, \mathrm{Z}_{3}, \mathrm{Z}_{5}, \mathrm{Z}_{10} \mathrm{Z}_{11}$ & $\mathrm{Z}_{12}$ & $\mathrm{Z}_{1}, \mathrm{Z}_{6}, \mathrm{Z}_{13}$ \\
\hline $\mathrm{Z}_{5}$ & $\mathrm{Z}_{2}, \mathrm{Z}_{4}, \mathrm{Z}_{6}, \mathrm{Z}_{7}, \mathrm{Z}_{10}$ & $\mathrm{Z}_{3}$ & $\mathrm{Z}_{11}$ \\
\hline $\mathrm{Z}_{6}$ & $\mathrm{Z}_{5}, \mathrm{Z}_{7}, \mathrm{Z}_{10}$ & $\mathrm{Z}_{9}$ & $\mathrm{Z}_{4}$ \\
\hline $\mathrm{Z}_{7}$ & $\mathrm{Z}_{5}, \mathrm{Z}_{6}$ & $\mathrm{Z}_{9}$ & $\mathrm{Z}_{10}$ \\
\hline $\mathrm{Z}_{8}$ & $\mathrm{Z}_{9}$ & $\mathrm{Z}_{10}$ & $\mathrm{Z}_{6}, \mathrm{Z}_{7}$ \\
\hline $\mathrm{Z}_{9}$ & $\mathrm{Z}_{8}, \mathrm{Z}_{10}, \mathrm{Z}_{11}$ & $\mathrm{Z}_{6}, \mathrm{Z}_{7}$ & $\mathrm{Z}_{5}$ \\
\hline $\mathrm{Z}_{10}$ & $\mathrm{Z}_{4}, \mathrm{Z}_{5}, \mathrm{Z}_{6}, \mathrm{Z}_{9} \mathrm{Z}_{11}$ & $\mathrm{Z}_{12}$ & $\mathrm{Z}_{7}$ \\
\hline $\mathrm{Z}_{11}$ & $\mathrm{Z}_{4}, \mathrm{Z}_{9}, \mathrm{Z}_{10}, \mathrm{Z}_{12}$ & $\mathrm{Z}_{3}, \mathrm{Z}_{13}$ & $\mathrm{Z}_{5}$ \\
\hline $1 Z_{12}$ & $\mathrm{Z}_{11}, \mathrm{Z}_{13}$ & $\mathrm{Z}_{3}, \mathrm{Z}_{4}$ & $\mathrm{Z}_{10}$ \\
\hline $\mathrm{Z}_{13}$ & $\mathrm{Z}_{3}, \mathrm{Z}_{12}$ & $\mathrm{Z}_{4}, \mathrm{Z}_{11}$ & $\mathrm{Z}_{1}, \mathrm{Z}_{10}$ \\
\hline
\end{tabular}$$
G_{Z_{6}}=1,00224444
$$$$
G_{Z_{7}}=1,00224444
$$$$
G_{Z_{8}}=1,00224444
$$$$
G_{Z_{9}}=1,00224444
$$$$
G_{Z_{10}}=1,00224444
$$

d. Kriteria Pengujian

Karena nilai indeks Gini bernilai 1 (satu) maka $H_{0}$ ditolak.

e. Kesimpulan

Keempat lokasi (Cirebon, Indramayu, Majalengka, dan Sukabumi) heterogen.

\section{Menentukan Matriks Bobot Lokasi}

Penentuan pasangan orde tiap variabel berdasarkan tetangga dengan jarak terdekat.

Tabel 3. Pasangan Orde Tiap Variabel

\section{Matriks Bobot Biner (Binary)}

Nilai dari bobot biner adalah 1 atau 0. Nilai tersebut ditentukan berdasarkan batasan tertentu. Untuk penelitian ini, nilai 1 diberikan pada kota/kabupaten dengan tetangga yang paling dekat. Berdasarkan tabel 3, dapat dibentuk matriks bobot biner dengan spasial lag 1, 2, dan 3. 


$$
\begin{aligned}
& W^{(1)}=\left(\begin{array}{ccccccccccccc}
0 & 1 & 0 & 0 & 0 & 0 & 0 & 0 & 0 & 0 & 0 & 0 & 0 \\
1 & 0 & 0 & 0 & 0 & 0 & 0 & 0 & 0 & 0 & 0 & 0 & 0 \\
0 & 0 & 0 & 1 & 0 & 0 & 0 & 0 & 0 & 0 & 0 & 0 & 0 \\
0 & 0 & 0 & 0 & 0 & 0 & 0 & 0 & 0 & 1 & 0 & 0 & 0 \\
0 & 0 & 0 & 0 & 0 & 1 & 0 & 0 & 0 & 0 & 0 & 0 & 0 \\
0 & 0 & 0 & 0 & 0 & 0 & 1 & 0 & 0 & 0 & 0 & 0 & 0 \\
0 & 0 & 0 & 0 & 0 & 1 & 0 & 0 & 0 & 0 & 0 & 0 & 0 \\
0 & 0 & 0 & 0 & 0 & 0 & 0 & 0 & 1 & 0 & 0 & 0 & 0 \\
0 & 0 & 0 & 0 & 0 & 0 & 0 & 1 & 0 & 0 & 0 & 0 & 0 \\
0 & 0 & 0 & 1 & 0 & 0 & 0 & 0 & 0 & 0 & 0 & 0 & 0 \\
0 & 0 & 0 & 0 & 0 & 0 & 0 & 0 & 0 & 0 & 0 & 1 & 0 \\
0 & 0 & 0 & 0 & 0 & 0 & 0 & 0 & 0 & 0 & 0 & 0 & 1 \\
0 & 0 & 0 & 0 & 0 & 0 & 0 & 0 & 0 & 0 & 0 & 1 & 0
\end{array}\right), W^{(2)}=\left(\begin{array}{lllllllllllll}
0 & 0 & 1 & 0 & 0 & 0 & 0 & 0 & 0 & 0 & 0 & 0 & 0 \\
0 & 0 & 1 & 0 & 0 & 0 & 0 & 0 & 0 & 0 & 0 & 0 & 0 \\
1 & 0 & 0 & 0 & 0 & 0 & 0 & 0 & 0 & 0 & 0 & 0 & 0 \\
0 & 0 & 1 & 0 & 0 & 0 & 0 & 0 & 0 & 0 & 0 & 0 & 0 \\
0 & 0 & 0 & 0 & 0 & 0 & 0 & 0 & 0 & 1 & 0 & 0 & 0 \\
0 & 0 & 0 & 0 & 1 & 0 & 0 & 0 & 0 & 0 & 0 & 0 & 0 \\
0 & 0 & 0 & 0 & 1 & 0 & 0 & 0 & 0 & 0 & 0 & 0 & 0 \\
0 & 0 & 0 & 0 & 0 & 0 & 0 & 0 & 0 & 1 & 0 & 0 & 0 \\
0 & 0 & 0 & 0 & 0 & 0 & 0 & 0 & 0 & 1 & 0 & 0 & 0 \\
0 & 0 & 0 & 0 & 1 & 0 & 0 & 0 & 0 & 0 & 0 & 0 & 0 \\
0 & 0 & 0 & 0 & 0 & 0 & 0 & 0 & 0 & 1 & 0 & 0 & 0 \\
0 & 0 & 0 & 0 & 0 & 0 & 0 & 0 & 0 & 0 & 1 & 0 & 0 \\
0 & 0 & 0 & 0 & 0 & 0 & 0 & 0 & 0 & 0 & 1 & 0 & 0
\end{array}\right), W^{(3)} \\
& =\left(\begin{array}{lllllllllllll}
0 & 0 & 0 & 1 & 0 & 0 & 0 & 0 & 0 & 0 & 0 & 0 & 0 \\
0 & 0 & 0 & 0 & 1 & 0 & 0 & 0 & 0 & 0 & 0 & 0 & 0 \\
0 & 1 & 0 & 0 & 0 & 0 & 0 & 0 & 0 & 0 & 0 & 0 & 0 \\
0 & 0 & 0 & 0 & 1 & 0 & 0 & 0 & 0 & 0 & 0 & 0 & 0 \\
0 & 0 & 0 & 1 & 0 & 0 & 0 & 0 & 0 & 0 & 0 & 0 & 0 \\
0 & 0 & 0 & 0 & 0 & 0 & 0 & 0 & 0 & 1 & 0 & 0 & 0 \\
0 & 0 & 0 & 0 & 0 & 0 & 0 & 0 & 0 & 1 & 0 & 0 & 0 \\
0 & 0 & 0 & 0 & 0 & 1 & 0 & 0 & 0 & 0 & 0 & 0 & 0 \\
0 & 0 & 0 & 0 & 0 & 1 & 0 & 0 & 0 & 0 & 0 & 0 & 0 \\
0 & 0 & 0 & 0 & 0 & 0 & 0 & 0 & 0 & 0 & 1 & 0 & 0 \\
0 & 0 & 0 & 1 & 0 & 0 & 0 & 0 & 0 & 0 & 0 & 0 & 0 \\
0 & 0 & 1 & 0 & 0 & 0 & 0 & 0 & 0 & 0 & 0 & 0 & 0 \\
0 & 0 & 1 & 0 & 0 & 0 & 0 & 0 & 0 & 0 & 0 & 0 & 0
\end{array}\right)
\end{aligned}
$$

\section{Matriks Bobot Seragam}

Nilai dari bobot seragam dihitung dengan rumus $w_{i j}=\frac{1}{n_{i}}$ dengan $n_{i}$ adalah jumlah lokasi yang berdekatan dengan $i$. Bobot lokasi ini memberikan nilai bobot yang sama untuk masing-masing lokasi. Berdasarkan tabel 3 dapat dibentuk matriks bobot seragam dengan spasial lag 1, 2, dan 3 .

$$
\begin{aligned}
& W^{(1)}=\left(\begin{array}{ccccccccccccc}
0 & 0,5 & 0,5 & 0 & 0 & 0 & 0 & 0 & 0 & 0 & 0 & 0 & 0 \\
0,25 & 0 & 0,25 & 0,25 & 0,25 & 0 & 0 & 0 & 0 & 0 & 0 & 0 & 0 \\
0,25 & 0,25 & 0 & 0,25 & 0 & 0 & 0 & 0 & 0 & 0 & 0 & 0 & 0,25 \\
0 & 0,2 & 0,2 & 0 & 0,2 & 0 & 0 & 0 & 0 & 0,2 & 0,2 & 0 & 0 \\
0 & 0,2 & 0 & 0,2 & 0 & 0,2 & 0,2 & 0 & 0 & 0,2 & 0 & 0 & 0 \\
0 & 0 & 0 & 0 & 0,33 & 0 & 0,33 & 0 & 0 & 0,33 & 0 & 0 & 0 \\
0 & 0 & 0 & 0 & 0,5 & 0,5 & 0 & 0 & 0 & 0 & 0 & 0 & 0 \\
0 & 0 & 0 & 0 & 0 & 0 & 0 & 0 & 1 & 0 & 0 & 0 & 0 \\
0 & 0 & 0 & 0 & 0 & 0 & 0 & 0,33 & 0 & 0,33 & 0,33 & 0 & 0 \\
0 & 0 & 0 & 0,2 & 0,2 & 0,2 & 0 & 0 & 0,2 & 0 & 0,2 & 0 & 0 \\
0 & 0 & 0 & 0,25 & 0 & 0 & 0 & 0 & 0,25 & 0,25 & 0 & 0,25 & 0 \\
0 & 0 & 0 & 0 & 0 & 0 & 0 & 0 & 0 & 0 & 0,5 & 0 & 0,5 \\
0 & 0 & 0,5 & 0 & 0 & 0 & 0 & 0 & 0 & 0 & 0 & 0,5 & 0
\end{array}\right) \\
& W^{(2)}=\left(\begin{array}{ccccccccccccc}
0 & 0 & 0 & 0,5 & 0 & 0 & 0 & 0 & 0 & 0 & 0 & 0 & 0,5 \\
0 & 0 & 0 & 0 & 0 & 0 & 0 & 0 & 0 & 0 & 0 & 0 & 1 \\
0 & 0 & 0 & 0 & 0 & 0 & 0 & 0 & 0 & 0 & 0,5 & 0,5 & 0 \\
0 & 0 & 0 & 0 & 0 & 0 & 0 & 0 & 0 & 0 & 0 & 1 & 0 \\
0 & 0 & 1 & 0 & 0 & 0 & 0 & 0 & 0 & 0 & 0 & 0 & 0 \\
0 & 0 & 0 & 0 & 0 & 0 & 0 & 0 & 1 & 0 & 0 & 0 & 0 \\
0 & 0 & 0 & 0 & 0 & 0 & 0 & 0 & 1 & 0 & 0 & 0 & 0 \\
0 & 0 & 0 & 0 & 0 & 0 & 0 & 0 & 0 & 1 & 0 & 0 & 0 \\
0 & 0 & 0 & 0 & 0 & 0,5 & 0,5 & 0 & 0 & 0 & 0 & 0 & 0 \\
0 & 0 & 0 & 0 & 0 & 0 & 0 & 0 & 0 & 0 & 0 & 1 & 0 \\
0 & 0 & 0,5 & 0 & 0 & 0 & 0 & 0 & 0 & 0 & 0 & 0 & 0,5 \\
0 & 0 & 0,5 & 0,5 & 0 & 0 & 0 & 0 & 0 & 0 & 0 & 0 & 0 \\
0 & 0 & 0 & 0,5 & 0 & 0 & 0 & 0 & 0 & 0 & 0,5 & 0 & 0
\end{array}\right), W^{(3)}=\left(\begin{array}{ccccccccccccc}
0 & 0 & 0 & 0 & 1 & 0 & 0 & 0 & 0 & 0 & 0 & 0 & 0 \\
0 & 0 & 0 & 0 & 0 & 0 & 0 & 0 & 0 & 1 & 0 & 0 & 0 \\
0 & 0 & 0 & 0 & 0,5 & 0 & 0 & 0 & 0 & 0,5 & 0 & 0 & 0 \\
0,33 & 0 & 0 & 0 & 0 & 0,33 & 0 & 0 & 0 & 0 & 0 & 0 & 0,33 \\
0 & 0 & 0 & 0 & 0 & 0 & 0 & 0 & 0 & 0 & 1 & 0 & 0 \\
0 & 0 & 0 & 1 & 0 & 0 & 0 & 0 & 0 & 0 & 0 & 0 & 0 \\
0 & 0 & 0 & 0 & 0 & 0 & 0 & 0 & 0 & 1 & 0 & 0 & 0 \\
0 & 0 & 0 & 0 & 0 & 0,5 & 0,5 & 0 & 0 & 0 & 0 & 0 & 0 \\
0 & 0 & 0 & 0 & 1 & 0 & 0 & 0 & 0 & 0 & 0 & 0 & 0 \\
0 & 0 & 0 & 0 & 0 & 0 & 1 & 0 & 0 & 0 & 0 & 0 & 0 \\
0 & 0 & 0 & 0 & 1 & 0 & 0 & 0 & 0 & 0 & 0 & 0 & 0 \\
0 & 0 & 0 & 0 & 0 & 0 & 0 & 0 & 0 & 1 & 0 & 0 & 0 \\
0,5 & 0 & 0 & 0 & 0 & 0 & 0 & 0 & 0 & 0,5 & 0 & 0 & 0
\end{array}\right)
\end{aligned}
$$




\section{Matriks Bobot Normalisasi Korelasi Silang}

Bobot lokasi normalisasi korelasi silang yaitu menggunakan hasil normalisasi korelasi silang antara lokasi pada lag waktu yang bersesuaian. Taksiran korelasi silang pada data sampel adalah [5]:

$$
r_{i j}(k)=\frac{\sum_{t=k+1}^{n}\left[z_{i}(t)-\bar{z}_{i}\right]\left[z_{j}(t-k)-\bar{z}_{j}\right]}{\sqrt{\left(\sum_{t=1}^{n}\left[z_{i}(t)-\bar{z}_{i}\right]^{2}\right)\left(\sum_{t=1}^{n}\left[z_{j}(t)-\bar{z}_{j}\right]^{2}\right)}}
$$

Menentukan bobot lokasi dengan normalisasi pada korelasi silang antar lokasi pada waktu yang bersesuaian untuk model GSTAR(1 $\left.1_{1}\right)$ sebagai berikut:

$$
w_{i j}=\frac{r_{i j}(1)}{\sum_{k \neq i}\left|r_{i k}(1)\right|}
$$

dimana $i \neq j, k=1, \ldots, p$ dan bobot memenuhi $\sum_{k \neq i}\left|w_{i j}\right|=1$. Sehingga diperoleh matriks bobot normalisasi korelasi silang sebagai berikut:

$$
W^{(1)}=\left(\begin{array}{ccccccccccccc}
0 & 0,086 & 0,088 & 0,072 & 0,08 & 0,082 & 0,082 & 0,088 & 0,088 & 0,076 & 0,083 & 0,087 & 0,088 \\
0,09 & 0 & 0,087 & 0,067 & 0,079 & 0,084 & 0,091 & 0,092 & 0,095 & 0,061 & 0,079 & 0,09 & 0,084 \\
0,088 & 0,086 & 0 & 0,073 & 0,08 & 0,08 & 0,086 & 0,089 & 0,091 & 0,07 & 0,079 & 0,092 & 0,086 \\
0,09 & 0,08 & 0,085 & 0 & 0,075 & 0,083 & 0,077 & 0,084 & 0,09 & 0,078 & 0,088 & 0,086 & 0,084 \\
0,088 & 0,085 & 0,084 & 0,075 & 0 & 0,078 & 0,091 & 0,092 & 0,092 & 0,062 & 0,077 & 0,091 & 0,084 \\
0,083 & 0,085 & 0,086 & 0,073 & 0,089 & 0 & 0,093 & 0,091 & 0,09 & 0,07 & 0,075 & 0,075 & 0,09 \\
0,082 & 0,09 & 0,084 & 0,071 & 0,084 & 0,087 & 0 & 0,095 & 0,099 & 0,056 & 0,079 & 0,081 & 0,093 \\
0,085 & 0,088 & 0,086 & 0,075 & 0,083 & 0,079 & 0,089 & 0 & 0,091 & 0,067 & 0,081 & 0,085 & 0,092 \\
0,085 & 0,086 & 0,086 & 0,071 & 0,082 & 0,086 & 0,093 & 0,094 & 0 & 0,068 & 0,081 & 0,082 & 0,088 \\
0,089 & 0,082 & 0,09 & 0,081 & 0,077 & 0,071 & 0,072 & 0,085 & 0,084 & 0 & 0,088 & 0,098 & 0,083 \\
0,088 & 0,083 & 0,09 & 0,076 & 0,078 & 0,077 & 0,081 & 0,089 & 0,087 & 0,08 & 0 & 0,086 & 0,085 \\
0,088 & 0,086 & 0,087 & 0,072 & 0,07 & 0,08 & 0,086 & 0,096 & 0,092 & 0,071 & 0,085 & 0 & 0,088 \\
0,091 & 0,084 & 0,089 & 0,073 & 0,082 & 0,077 & 0,085 & 0,091 & 0,09 & 0,068 & 0,081 & 0,89 & 0
\end{array}\right)
$$

\subsection{Pembentukan model}

\section{Identifikasi Model}

Tahap awal pembentukan model yaitu identifikasi model dengan melihat nilai STACF dan STPACF. Berikut ini nilai STACF dan STPACF data jumlah TKI dengan $N=13$ dan $T=29$ dengan matriks

\begin{tabular}{|c|c|c|c|c|c|c|c|c|c|c|}
\hline Bobot & Biner & Seragam & Korelasi & Biner & Seragam & Korelasi & Biner & Seragam & Biner & Seragam \\
\hline Spasial lag $(l)$ & \multicolumn{3}{|c|}{0} & \multicolumn{3}{|c|}{1} & \multicolumn{2}{|r|}{2} & \multicolumn{2}{|r|}{3} \\
\hline Time lag $(s)$ & & & & & & & & & & \\
\hline 1 & 0,9095 & 0,909489 & 0,909489 & 0,565 & 0,743037 & 0,746467 & 0,722 & 0,431456 & 0,475 & 0,539746 \\
\hline 2 & 0,8301 & 0,830104 & 0,830104 & 0,517 & 0,678403 & 0,683229 & 0,662 & 0,397478 & 0,435 & 0,498859 \\
\hline 3 & 0,7411 & 0,741105 & 0,741105 & 0,455 & 0,604005 & 0,607612 & 0,6 & 0,352677 & 0,393 & 0,449003 \\
\hline 4 & 0,6774 & 0,677386 & 0,677386 & 0,416 & 0,554549 & 0,559052 & 0,562 & 0,323046 & 0,363 & 0,41678 \\
\hline
\end{tabular}
bobot biner, seragam, dan korelasi silang:

Tabel 4. Nilai STACF Space Time Autocorrelation Function $\widehat{\rho}_{l 0}(s)$ 
Tabel 5. Nilai STPACF Space Time Partial Autocorrelation Function

\begin{tabular}{|c|c|c|c|c|c|c|c|c|c|c|}
\hline Bobot & Biner & Seragam & Korelasi & Biner & Seragam & Korelasi & Biner & Seragam & Biner & Seragam \\
\hline Spasial lag $(l)$ & & 0 & & & 1 & & & 2 & & 3 \\
\hline \multicolumn{11}{|l|}{ Time lag $(s)$} \\
\hline 1 & 0,942 & 0,941971 & 0,941971 & 0,018 & 0,017004 & 0,023436 & 0,002 & 0,002889 & $-0,005$ & $-0,005055$ \\
\hline 2 & 0,0043 & 0,004283 & 0,004283 & $-0,02$ & $-0,01589$ & $-0,01997$ & -0 & 0,001743 & 0,005 & 0,007815 \\
\hline 3 & $-0,901$ & $-0,900547$ & $-0,90055$ & 0,582 & 0,738401 & 0,848543 & 0,204 & $-0,06552$ & 0,045 & 0,075897 \\
\hline 4 & $-1,72$ & $-1,720046$ & $-1,72005$ & 1,176 & 1,471392 & 1,695349 & 0,388 & $-0,12584$ & 0,079 & 0,145085 \\
\hline
\end{tabular}

Nilai dari STACF menggunakan matriks biner, seragam, dan korelasi silang jatuh turun secara signifikan (tail off quickly at all spasial lag), sehingga datanya nampak stasioner. Dengan melihat nilai STPACF terpotong (cut off) setelah $s=1$ untuk $l=0$ dan $l=1$, sehingga model kandidat yang dapat dibangun adalah model GSTAR(10) dan GSTAR(1 1 ).

\section{Estimasi Parameter}

Estimasi parameter dilakukan sesuai matriks bobot lokasi yang digunakan. Untuk semua nilai STACF dan STPACF dari matriks bobot biner, seragam, dan korelasi silang diperoleh kandidat model kandidat untuk data TKI Jawa Barat adalah model GSTAR(10) dan GSTAR(1 1 ). Estimasi parameter Model GSTAR(10) dihitung dengan bantuan software Minitab11.

Taksiran model GSTAR(10) sebagai berikut:

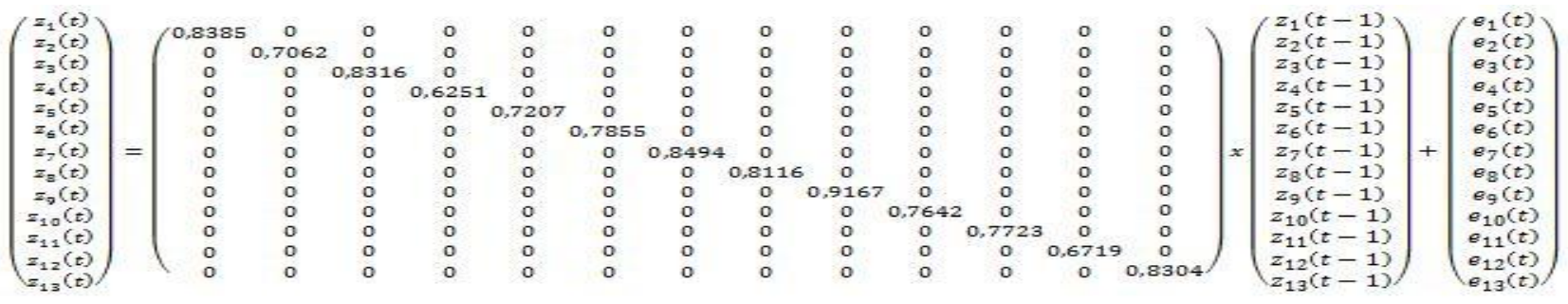

Taksiran persamaan model GSTAR(11) dengan menggunakan matriks bobot biner sebagai berikut:

\begin{tabular}{|c|c|c|c|c|c|c|c|c|c|c|c|c|c|c|c|c|c|c|}
\hline$z_{1}$ & & 1,0178 & 1,0793 & 0 & 0 & 0 & 0 & 0 & 0 & 0 & 0 & 0 & 0 & 0 & & $\left(\begin{array}{l}z_{1}(t-1) \\
z_{1}(t-1)\end{array}\right)$ & & $\left(\begin{array}{l}e_{1}(t) \\
\theta_{2}(t)\end{array}\right)$ \\
\hline$z_{2}(t)$ & & $-0,0401$ & $-0,1307$ & 0 & 0 & 0 & 0 & 0 & 0 & 0 & 0 & 0 & 0 & 0 & & $z_{2}(t-1)$ & & $\theta_{2}(t)$ \\
\hline$z_{3}(t)$ & & 0 & 0 & 0,8042 & 0,0793 & 0 & 0 & 0 & 0 & 0 & 0 & 0 & 0 & 0 & & $z_{3}(t-1)$ & & $e_{3}(t)$ \\
\hline$z_{4}(t)$ & & 0 & 0 & 0 & 0,2343 & 0 & 0 & 0 & 0 & 0 & 2,2761 & 0 & 0 & 0 & & $z_{4}(t-1)$ & & $e_{4}(t)$ \\
\hline$z_{5}(t)$ & & 0 & 0 & 0 & 0 & 0,6431 & 0,7893 & 0 & 0 & 0 & 0 & 0 & 0 & 0 & & $z_{5}(t-1)$ & & $e_{5}(t)$ \\
\hline$z_{6}(t)$ & & 0 & 0 & 0 & 0 & 0 & 0,2238 & 0,1367 & 0 & 0 & 0 & 0 & 0 & 0 & & $z_{6}(t-1)$ & & $e_{6}(t)$ \\
\hline$z_{7}(t)$ & $=$ & 0 & 0 & 0 & 0 & 0 & 0,7893 & 0,8044 & 0 & 0 & 0 & 0 & 0 & 0 & $x$ & $z_{7}(t-1)$ & + & $e_{7}(t)$ \\
\hline$z_{g}(t)$ & & 0 & 0 & 0 & 0 & 0 & 0 & 0 & 0,088 & 0,7764 & 0 & 0 & 0 & 0 & & $z_{8}(t-1)$ & & $e_{8}(t)$ \\
\hline$z_{0}(t)$ & & 0 & 0 & 0 & 0 & 0 & 0 & 0 & 0,495 & 0,5359 & 0 & 0 & 0 & 0 & & $z_{9}(t-1)$ & & $e_{9}(t)$ \\
\hline$z_{10}(t)$ & & 0 & 0 & 0 & 0,0793 & 0 & 0 & 0 & 0 & 0 & 0,6964 & 0 & 0 & 0 & & $z_{10}(t-1)$ & & $e_{10}(t)$ \\
\hline$z_{11}(t)$ & & 0 & 0 & 0 & 0 & 0 & 0 & 0 & 0 & 0 & 0 & 0,5045 & 0,3222 & 0 & & $z_{11}(t-1)$ & & $e_{11}(t)$ \\
\hline & & 0 & 0 & 0 & 0 & 0 & 0 & 0 & 0 & 0 & 0 & 0 & 0,5897 & 0,4465 & & & & 100 \\
\hline & & 0 & 0 & 0 & 0 & 0 & 0 & 0 & 0 & 0 & 0 & 0 & 0,3222 & 0,5099 & & & & \\
\hline
\end{tabular}

Taksiran persamaan model GSTAR(11) dengan menggunakan matriks bobot seragam sebagai berikut:

\begin{tabular}{|c|c|c|c|c|c|c|c|c|c|c|c|c|c|c|c|c|c|c|}
\hline$z_{2}(t)$ & & $(1,1149$ & 1,1928 & 0,9506 & 0 & 0 & 0 & 0 & 0 & 0 & 0 & 0 & 0 & 0 & & $z_{1}(t-1)$ & & $e_{1}(t)$ \\
\hline$z_{z}(t)$ & & $-0,0377$ & $-0,7664$ & 0,4753 & 0,0571 & 0,0932 & 0 & 0 & 0 & 0 & 0 & 0 & 0 & 0 & & $z_{2}(t-1)$ & & $e_{2}(t)$ \\
\hline$z_{z}(t)$ & & $-0,0377$ & 0,5964 & $-0,4285$ & 0,0571 & 0 & 0 & 0 & 0 & 0 & 0 & 0 & 0 & 0,0809 & & $z_{3}(t-1)$ & & $e_{3}(t)$ \\
\hline$z_{4}(t)$ & & 0 & 0,4771 & 0,3802 & $-0,0851$ & 0,0746 & 0 & 0 & 0 & 0 & 0,1491 & 0,1404 & 0 & 0 & & $z_{4}(t-1)$ & & $e_{4}(t)$ \\
\hline$z_{2}(t)$ & & 0 & 0,4771 & 0 & 0,0457 & 0,5207 & 0,0457 & 0,0046 & 0 & 0 & 0,1491 & 0 & 0 & 0 & & $z_{5}(t-1)$ & & $e_{5}(t)$ \\
\hline$z_{0}(t)$ & & 0 & 0 & 0 & 0 & 0,1231 & 0,3343 & 0,0076 & 0 & 0 & 0,2460 & 0 & 0 & 0 & & $z_{6}(t-1)$ & & $e_{6}(t)$ \\
\hline$z,(t)$ & $=$ & 0 & 0 & 0 & 0 & 0,1865 & 0,1142 & 0,9053 & 0 & 0 & 0 & 0 & 0 & 0 & $x$ & $z_{7}(t-1)$ & + & $e_{7}(t)$ \\
\hline$\Sigma_{g}(t)$ & & 0 & 0 & 0 & 0 & 0 & 0 & 0 & 0,0880 & 0,1172 & 0 & 0 & 0 & 0 & & $z_{g}(t-1)$ & & $e_{3}(t)$ \\
\hline$z_{p}(t)$ & & 0 & 0 & 0 & 0 & 0 & 0 & 0 & 0,1634 & 0,8984 & 0,2460 & 0,2316 & 0 & 0 & & $z_{g}(t-1)$ & & $e_{g}(t)$ \\
\hline$z_{20}(t)$ & & 0 & 0 & 0 & 0,0457 & 0,0746 & 0,0457 & 0 & 0 & 0,0234 & 0,7068 & 0,1404 & 0 & 0 & & $z_{10}(t-1)$ & & $e_{10}(t)$ \\
\hline$z_{1},(t)$ & & 0 & 0 & 0 & 0,0571 & 0 & 0 & 0 & 0 & 0,0293 & 0,1864 & $-0,3030$ & 0,0740 & 0 & & $z_{11}(t-1)$ & & $e_{1}(t)$ \\
\hline $8,1(t)$ & & 0 & 0 & 0 & 0 & 0 & 0 & 0 & 0 & 0 & 0 & 0,3509 & 0,5698 & 0,1618 & & $z_{12}(t-1)$ & & $=(t)$ \\
\hline$z_{12}(t)$ & & 0 & 0 & 0,9506 & 0 & 0 & 0 & 0 & 0 & 0 & 0 & 0 & 0,1479 & 0,4153 & & (4) 17 & & t) \\
\hline
\end{tabular}


Taksiran persamaan model GSTAR(1 1 ) dengan menggunakan matriks bobot korelasi silang sebagai berikut:

\begin{tabular}{|c|c|c|c|c|c|c|c|c|c|c|c|c|c|c|c|c|c|}
\hline$z_{2}(t)$ & & 1,0113 & 0,1333 & 0.1212 & 0203 & 0692 & 0,0344 & 0066 & 0738 & 0,0384 & 748 & 0,0633 & & 0,03 & & 1) & \\
\hline$z_{2}(t)$ & & $-0,0040$ & $-0,2133$ & 0,1203 & 0,0188 & 0,0684 & 0,0352 & 0,0074 & 0,0777 & 0,0417 & 0,0597 & 0,0596 & 0,0163 & 0,0321 & & & \\
\hline$z_{z}(t)$ & & $-0,0039$ & 0,1336 & $-0,2717$ & 0,0205 & 0,0696 & 0,0335 & 0,0069 & 0,0751 & 0,0396 & 0,0690 & 00 & 0,0166 & 0,0328 & & & $e_{3}(t)$ \\
\hline$z_{4}(t)$ & & $-0,0040$ & 0,1247 & 0,1170 & $-0,0919$ & 0,0645 & 0,03 & 0,0063 & 0,0709 & 0,0394 & 0,0761 & 69 & 0,0155 & 0,0321 & & & $e_{4}(t)$ \\
\hline$z_{3}(t)$ & & $-0,0039$ & 0,1332 & 0,1 & 0,0 & $-0,0693$ & 0,0 & 3 & 0,0774 & 0,0 & 11 & & 54 & 0 , & & sect & $e_{5}(t)$ \\
\hline$z_{0}(t)$ & & $-0,0036$ & 0,1320 & 0,1180 & 6 & & -0 & 0,0075 & 0,0 & 94 & 36 & 71 & 7 & 3 & & $6(t$ & $e_{6}(t)$ \\
\hline$z,(t)$ & $=$ & $-0,0036$ & 0,1396 & 0,1158 &, 0201 & 0726 & 0,0364 & 0,7540 & 0,0 & 0,0 & 0,0545 & 00 & 147 & 0,0352 & & $7(t-$ & $e_{7}(t)$ \\
\hline$z_{v}(t)$ & & $-0,0038$ & 0,1374 & 0,1183 &, 0209 & .0716 & 0,0329 & 0,0071 & 0,2440 & 0,0398 & 0,0661 & 0,0614 & 0,0153 & 0,0351 & & $8(t-$ & $88(t)$ \\
\hline$z_{\phi}(t)$ & & $-0,0038$ & 0,1335 &, 1183 & 0198 &, 0713 & 0,0359 & 0,0075 & 0,0787 & 0,7844 & 0,0667 & 0,0612 & 49 & 0,0 & & 29 & $\theta g(t)$ \\
\hline$(t)$ & & $-0,0039$ & 0,1284 & 0,1237 & 0,0229 & 0,0668 & 0,0296 & 0,0058 & 0,0710 & 0,0369 & 0,6155 & 0,0665 & 0,0177 & 0,0 & & & $8_{10}(t)$ \\
\hline & & $-0,0039$ & 0,1290 & 0,1 & 0,0213 & 0,0677 & 22 & 0,0065 & 0,0749 & 0,0380 & 0,0784 & $-0,1055$ & 0,0157 & 0,0 & & & $e_{11}(t$ \\
\hline & & 039 & 0,1336 & & & & 0,0 & 0,0070 & 0,0810 & 0,0 & 0,0693 & 842 & 552 & 0,0337 & & & \\
\hline & & & ,1308 & 20 & 0,0205 & & 4 & 69 & & 94 & 69 & 16 & 161 & 0,2567 & & $z_{13}(t-1)$ & \\
\hline
\end{tabular}

\section{Pemeriksaan Syarat Stasioner}

Nilai estimasi parameter GSTAR(10) nilainya harus terbatas pada $-1<\Phi_{1}<1$, lihat taksiran model GSTAR(10) bahwa semua parameter GSTAR(10) sudah memenuhi syarat tersebut. Sedangkan model GSTAR(11) dilakukan pemeriksaan syarat stasioner pada parameter yang diperoleh dari hasil OLS.

Pemeriksaan syarat stasioner parameter GSTAR $\left(1_{1}\right)$ menggunakan syarat kestasioneran parameter $\operatorname{VAR}(1)$ yaitu jika akar-akar $\Lambda$ dari $\left|I_{4} \lambda-\Phi_{1}\right|=0$ berada di luar lingkaran satuan artinya ekivalen bahwa syarat kestasioneran model VAR(1) nilai eigen dari $\Phi$ berada dalam lingkaran satuan atau $|\lambda|<1$.

Tabel 6. Nilai Eigen Tiap Matriks Bobot

\begin{tabular}{|c|c|c|c|c|c|c|c|c|c|c|c|c|c|}
\hline Eigen & lamda1 & lamda2 & lamdas & lamda4 & lamdab & lamdab & lamda 7 & lamdas & lamda $\theta$ & lamda10 & lamda11 & lamda12 & lamda1s \\
\hline Serasam & $1,1900>1$ & $0,3918<1$ & $0,2742<1$ & $1,0243>1$ & $0,9735<1$ & $0,9109<1$ & $0,8019<1$ & $0,7096<1$ & $0,5996<1$ & $0,4167<1$ & $0,9090<1$ & $0,0827<1$ & $0,0649<1$ \\
\hline Biner & $0.8042<1$ & $0.6431<1$ & $0.5045<1$ & $0.0185<1$ & $0.9490<1$ & $0.0757<1$ & $0.9525<1$ & $0.3472<1$ & $0.9711<1$ & $0.0917<1$ & $0.9788<1$ & $0.9512<1$ & $.1684<1$ \\
\hline $\begin{array}{c}\text { Korolasi } \\
\text { Silans: }\end{array}$ & $0.9848<1$ & $0.9486<1$ & $0.7458<1$ & $0.6573 \times 1$ & $0.5472<1$ & $0.3592<1$ & $0.2096<1$ & $0.3748<1$ & $0.2681<1$ & $0.0517<1$ & $0.0684<1$ & $0.1596<1$ & $1180<1$ \\
\hline
\end{tabular}

Dapat dilihat pada Tabel 6, bahwa dua nilai eigen untuk model GSTAR(1 $\left.1_{1}\right)$ dengan matriks bobot seragam tidak memenuhi $|\lambda|<1$ berarti GSTAR(1 $\left.1_{1}\right)$ dengan menggunakan matriks bobot seragam tidak stasioner, sedangkan semua nilai eigen untuk model GSTAR $\left(1_{1}\right)$ dengan matriks bobot biner maupun matriks korelasi silang memenuhi $|\lambda|<1$, maka dapat disimpulkan bahwa model GSTAR $\left(1_{1}\right)$ dengan matriks bobot biner dan matriks korelasi silang dalam kondisi stasioner, sehingga model untuk memodelkan data jumlah TKI Jawa Barat adalah GSTAR $\left(1_{0}\right)$ dan GSTAR(1 $\left.1_{1}\right)$ dengan matriks bobot biner dan matriks korelasi silang.

\section{Pemilihan Model Terbaik}

Berikut nilai RMSE sesuai persamaan untuk masing-masing model GSTAR dengan $N=13$ dan $T=2$

Tabel 7. Nilai RMSE Tiap Model GSTAR

\begin{tabular}{|l|c|}
\hline \multicolumn{1}{|c|}{ Model } & Nilai RMSE \\
\hline GSTAR(10) & $\mathbf{2 1 , 4 6 5 1}$ \\
\hline GSTAR(1 1 ) Bobot Biner & 75,996 \\
\hline GSTAR(1 $\left.1_{1}\right)$ Bobot Korelasi Silang & 31,37 \\
\hline
\end{tabular}

Berdasarkan Tabel 7, dapat diketahui bahwa tingkat ketepatan ramalan model GSTAR untuk 13 lokasi dengan nilai RMSE terkecil yaitu 21,4651 terdapat pada model GSTAR(10). Dengan demikian dapat disimpulkan bahwa model terbaik yang melibatkan 13 lokasi adalah model GSTAR(10). 


\section{Simpulan}

Berdasarkan hasil penelitian dan analisis yang dilakukan diperoleh beberapa kesimpulan, yang pertama, lokasi yang terpilih hasil pengelompokan metode DBSCAN pada data jumlah TKI Jawa Barat sebanyak 13 lokasi yaitu Cirebon, Indramayu, Majalengka, Sumedang, Subang, Purwakarta, Karawang, Sukabumi, Cianjur, Bandung, Garut, Tasikmalaya, dan Ciamis. Kedua, Model yang dapat dibentuk adalah model GSTAR(10), GSTAR(1 $\left.1_{1}\right)$ bobot biner, dan GSTAR(1 $\left.1_{1}\right)$ bobot korelasi silang. Model terbaik untuk data jumlah TKI Jawa Barat dengan nilai RMSE terkecil sebesar 21,4651 adalah model GSTAR(10) artinya data jumlah TKI tiap kabupaten di Jawa Barat hanya dipengaruhi faktor waktu dan tidak dipengaruhi langsung oleh jumlah kabupaten lainnya.

Untuk penelitian selanjutnya diharapkan mengkaji model GSTAR orde lainnya. Serta berdasarkan hasil penelitian diharapkan pemerintah Pemprov Jawa Barat melakukan langkahlangkah untuk mengatasi permasalahan TKI yang semakin bulan semakin meningkat.

\section{Daftar Pustaka}

1. Mukhaiyar, U. \& Pasaribu U.S., 2012, A New Procedure of Generalized STAR Modeling Using IAcM Approach. Jurnal ITB J. Sci., Vol. 44A(2), pp. 179-192.

2. Nurhayati, N., Pasaribu, U. S. \& Neswan, O., 2012, Application of Generalized Space-Time Autoregressive Model on GDP Data in West European Countries. Journal of Probability and Statistics.

3. Pfeifer, P.E. \& Deutsch, S. J., 1980, A Three-Stage Iterative Procedure For Space-Time Modeling, Technometrics, Vol. 22(1) pp. 35-47.

4. Ruchjana, B.N. 2002, Suatu Model Generalisasi Space Time Autoregresi dan Penerapannya pada Data produksi Minyak Bumi, Disertasi, Tidak Dipublikasikan. Program Pascasarjan ITB, Bandung.

5. Ruchjana, B.N., Borovkova, S.A., and Lopuhaa, H.P., 2012, Least squares estimation of Generalized Space Time AutoRegressive (GSTAR) model and its properties, The $5^{\text {th }}$ International Conferences on Research and Education in Mathematics, American Institute of Physics Conference Proceedings . 1450, pp 61 -64 (2012). 